\title{
A summary of the development of the NI CE Patient experience in adult NHS services guidance and quality standard with a perspective of its relevance in a Canadian context
}

\author{
Liz Avital, Eloise Carr, Sophie Staniszewska \\ National Clinical Guideline Centre UK, University of Calgary, Royal College of Nursing Research Institute, UK \\ Correspondence: Liz Avital. Address: 11 St Andrews Place, Regents Park, London NW1 4LE, UK. Email: \\ Liz.Avital@rcplondon.ac.uk.
}

Received: November 2, 2012

Accepted: January 3, 2013

Online Published: February 27, 2013

DOI : $10.5430 /$ jnep.v3n9p70

URL: http://dx.doi.org/10.5430/jnep.v3n9p70

\section{Abstract}

Background: In the United Kingdom patient experience is being established as a key determinant in informing commissioning decisions and in shaping healthcare delivery. This led to the publication of the National Institute for Health and Clinical Excellence (NICE) guidance on patient experience in adult National Health Service (NHS) services: improving the experience of care for people using adult NHS services (CG138) in February 2012.

Purpose: To develop guidance and a quality standard for NICE on patient experience in adult NHS services.

Methods: Guidance development by a multidisciplinary group using multiple evidence sources, distilled into five key themes of patient experience.

Results: Guidance including sixty recommendations, and a quality standard, developed from the synthesis of multiple sources of information.

Conclusion: This guidance has international applicability particularly in Canada.

\section{Key words}

Patient experience, Evidence sources, Guidance, Quality standard

\section{I ntroduction}

It is well documented that the National Health Service (NHS) in the United Kingdom (UK) has made good progress in the improvement of the quality of care ${ }^{[1]}$. However, such improvements and their measures often fail to explore the patients' experience as individual recipients of healthcare and establish what is important for them. Despite this, patient experience is establishing itself as a key determinant in informing commissioning decisions and in shaping healthcare delivery with it having been prioritised by the previous and current Coalition governments, and being the focus of a number of current work streams commissioned by the Department of Health ${ }^{[1]}$. The rise in importance of patient experience is not exclusive to the UK, as illustrated by the growth of organisations such as the International Alliance of Patient Organizations. 
The National Institute for Health and Clinical Excellence (NICE) guidance on patient experience in adult NHS services: improving the experience of care for people using adult NHS services (CG138) was published in February 2012. The guidance focuses on generic adult patient experiences and is relevant for all people using adult NHS services. It does however exclude mental health services which are addressed in guidance specific to mental health: Service user experience in adult mental health (CG136). It is non population and non setting specific making it a unique piece of guidance that can be applied across a range of contexts/settings ${ }^{[2]}$. The guidance and accompanying quality standard was developed to be used by all staff that provide services in the NHS, thus encapsulating both clinical and non clinical staff. It is directed at clinical and non clinical staff as it is recognised that the impact on a patient's experience of care is influenced by all staff members, they meet on their individual patient journey, no matter what their role.

The intention behind the development of this guidance and quality standard was to produce a document which could be used as the basis to facilitate change in the approach to the provision of patient care resulting in a good patient experience.

\section{Method}

\subsection{Guidance development group}

The guidance was developed by a multidisciplinary group, comprising of ten healthcare professional/academic members and six patient/carer members. The group was supported by a technical team from the National Clinical Guideline Centre (NCGC). The technical team included a project manager, systematic reviewer, health economist and information scientist who provided methodological support and guidance for the development process. The team undertook systematic searches of the literature, appraised the clinical evidence and cost effectiveness analysis where appropriate and presented their findings to the GDG. In turn, the GDG interpreted and debated the evidence from which they created the recommendations and drafted the guidance in collaboration with the technical team. The patient/carer representatives were supported by both the technical team and a representative from the patient and public involvement programme from the NICE. This guidance development group, like all such groups was recruited through a process of open recruitment; an advert is placed on the NICE website, applications are submitted, those identified as suitable are selected for interview. Prior to the advert the types of healthcare professionals wanted were outlined to ensure the group was reflective of as many areas of health care as possible. The patient/carer representatives were recruited in the same way, with the intention of providing the broadest patient perspective possible. In general, guideline development groups have only two patient/carer members, yet it was felt that for the development of this guidance, the group would strongly benefit from a greater number of patient / carer representatives.

\subsection{Evidence sources and key themes}

To ensure the guidance development group had multiple sources of evidence/information to establish what is important to patients when considering their experience of healthcare the following key sources were used :

1) A review of existing patient experience frameworks was carried out. Frameworks that have been influential were identified and reviewed. These included; the Institute of Medicine framework and the Picker principles both of which have been developed from the work of Gerteis and colleagues ${ }^{[3]}$, US National Health Council report $2004^{[4]}$, and the International Alliance Patients’ Organisations (IAPO).

2) A Patient Experience Scoping Study (the Warwick Patient Experiences Framework); to identify generic themes and sub themes of patient experience in three clinical areas; cardiovascular disease, diabetes and cancer ${ }^{[5]}$.

3) A review of NHS survey results; NHS national patient survey. 
4) A review of existing NICE recommendations from published guidelines considered relevant to patient experience were extracted from existing Clinical and Cancer Care guidelines published between the 1st January 2008 and 26th January 2011. Only recommendations relevant to adults were considered for inclusion.

5) Systematic reviews of the literature on prioritised topic.

Information from and discussion of the existing frameworks, the scoping study, the review of survey results and existing NICE recommendations resulted in the GDG identifying the following key themes of patient experience.

- Knowing the patient as an individual

- Essential requirements of care

- Tailoring healthcare services for patients

- Continuity of care and relationships

- Enabling patients to participate in their care.

The following diagram is an illustration of how these information sources feed into one another.

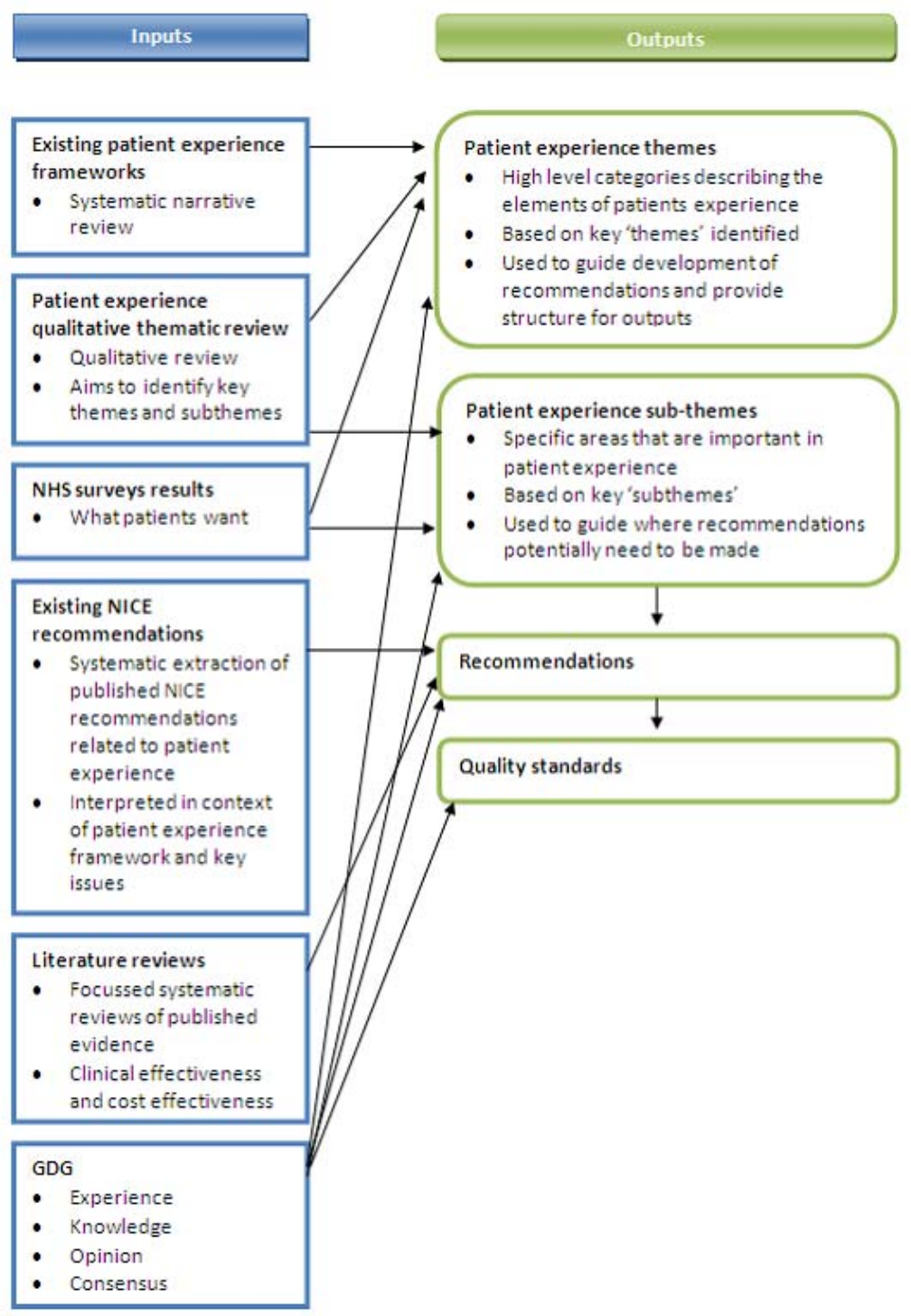

Figure 1. A summary of the evidence sources used in the development of the guidance (6). 


\section{Results}

Sixty eight recommendations (http://www.nice.org.uk/nicemedia/live/13668/58284/58284.pdf) were developed under the above mentioned key themes of patient experience, using all five sources of information.

These recommendations were further distilled to create 14 quality statements which make up the NICE quality standard, which are outlined in Table 1. The quality standard aims to improve standards of care by providing high level indicators. The quality statements are patient focused and are for service providers, healthcare professionals, commissioners and patients against which to drive and measure improvement to ensure a good patient experience ${ }^{[2]}$.

Table 1. Patient Experience Quality Standard ${ }^{[7]}$

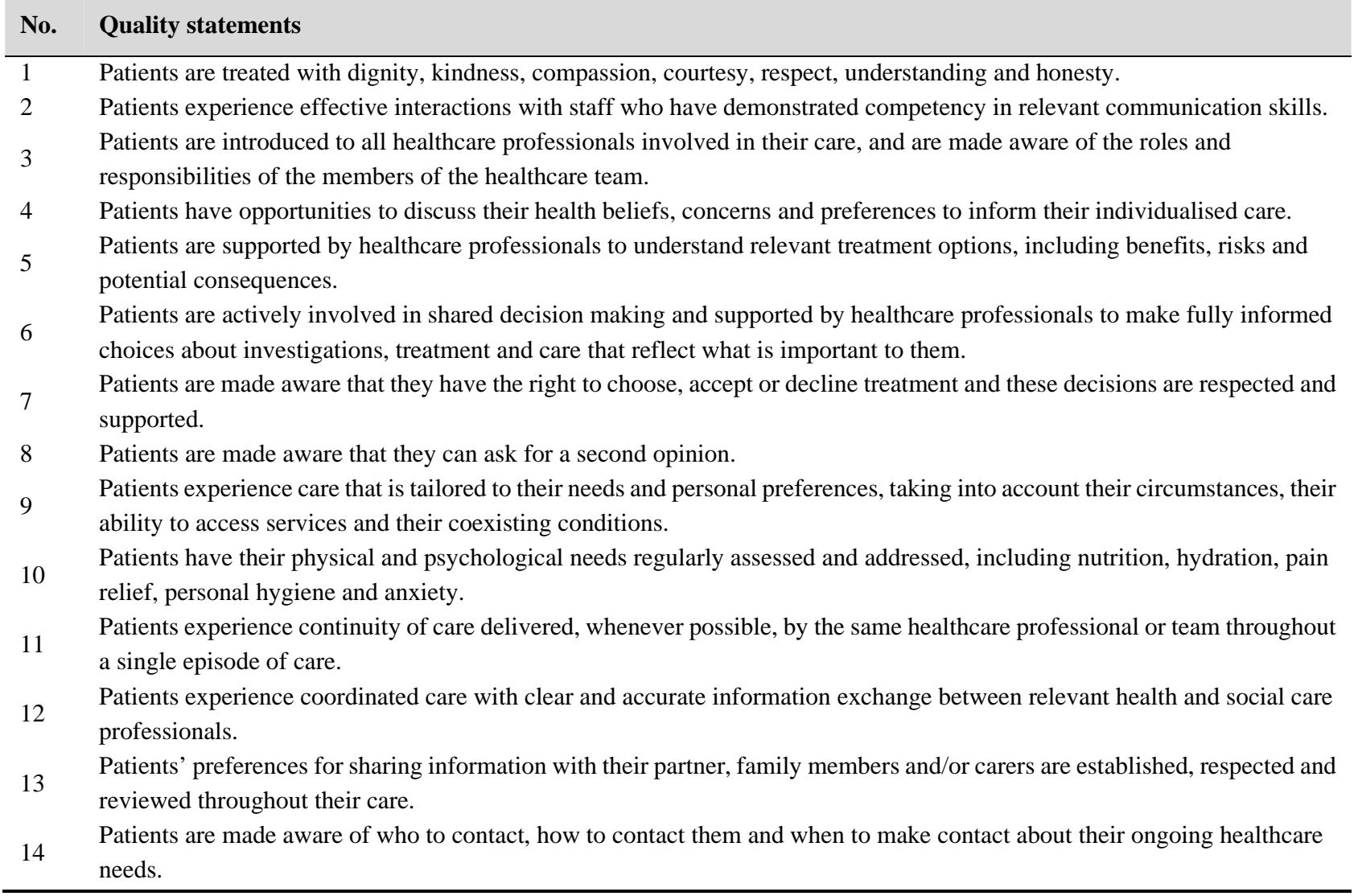

\section{Discussion}

As can be seen from these statements and has been discussed, this guidance is very generic in its nature. In such, this makes its resonance in the international arena very relevant as its core principles are those which can be applied regardless of the type of patient, context or setting. The robustness of the translation of this piece of work to an international context is supported by its use of high quality evidence, professional consensus and most importantly, the inclusion of the patient perspective and preference ${ }^{[8]}$. As such it represents a landmark in the development of patient-based guidance.

In Canada the Royal Commission on the Future of Health Care in Canada, also known as the Romanov Report ${ }^{[9]}$, was published in 2002. It set out the future for Canada's Health Care System and incorporated a far-reaching, multi-faceted approach. Included in the document was a chapter pertaining to the improvement of access and ensuring quality. Whilst not specific at the level of delivery of care and the patient experience, it nonetheless emphasized the importance of the patient experience. The Canadian Medical Association (CMA) and the Canadian Nurses Association (CAN) were more 
direct and published a number of principles to guide the transformation of the health care system in Canada ${ }^{[10]}$. These included the principal of patient-centered care, which considers the individual needs and preferences of the patient and his/her family, and to treat the patient with respect and dignity. Following the publication of this document they conducted a telephone survey of 1,100 Canadians to examine the public's views on these proposed principles ${ }^{[11]}$.

\section{Conclusion}

The findings demonstrate that the quality of the health care system remains the most important aspect to Canadians. In May of 2012 the CMA announced that 15 patient advocacy groups had endorsed the principals, jointly created by doctors and nurses, and called for the government at all levels to use these as a basis for health transformation ${ }^{[12]}$. The Patient Experience Guidance and Quality Standard has been well received in the UK and is continually referred to in NICE guidelines. It would therefore seem timely and fitting that this guidance and quality standard would have significant resonance with those calling for transformation in health care in Canada.

\section{Conflicts of interest}

The authors report no conflicts of interest. No financial payment received for the writing of this article.

\section{References}

[1] National Clinical Guideline Centre. Patient experience in adult NHS services: improving the experience of care for people using adult NHS services. Patient experience in generic terms (CG138). London: National Clinical Guideline Centre. 2012: 10. Available from: http://guidance.nice.org.uk/CG138

[2] Avital, L, Gager, M, Gibb A. New measures to improve patients' experiences of care. Nursing Management. 2012; 19(1).

[3] Gerteis M, Edgman-Levitan S, Daley J, Delbanco T. Through the patient's eyes: understanding and promoting patient-centered care. San Fransisco: Jossey-Bass; 1993

[4] Cronin, C. Patient -centered care: an overview of definitions and concepts. Washington, DC: National Health Council, 2004

[5] Staniszewska S, Boardman F, Gunn L, Palmer J, Clay D, Seers K, Brett J. 2011). Patient Experiences: A scoping study. Warwick: RCN Research Institute, University of Warwick (75\%). Report attached to NICE Guidance on Patient Experiences in Adult Services. Available from: http://guidance.nice.org.uk/CG138/Guidance/pdf/English

[6] National Clinical Guideline Centre. Patient experience in adult NHS services: improving the experience of care for people using adult NHS services. Patient experience in generic terms (CG138), p18. London: National Clinical Guideline Centre. 2012 Available from: http://guidance.nice.org.uk/CG138

[7] Patient experience in adult NHS services. Quality standard (QS15) issued February 2012. Available from: http://guidance.nice.org.uk/QS15

[8] Rycroft-Malone J. The PARIHS Framework. A Framework for Guiding the Implementation of Evidence-based Practice. Journal of Nursing Care Quality. 2004; 19(4): 297-304. PMid:15535533 http://dx.doi.org/10.1097/00001786-200410000-00002

[9] Romanow RJ. Building on values: the future of health care in Canada. Saskatoon: Commission on the Future of Health Care in Canada; 2002

[10] Canadian Medical Association (CMA) and the Canadian Nurses Association (CNA). Principals to Guide Health Transformation in Canada, 2011. Available from: www.cma.ca/advocacy/hctprinciples [accessed 12th October 2012]

[11] Public Attitudes towards Principals to Guide Health Care Transformation in Canada. 2011. Available from: http://www.ekos.com/admin/articles/CMAFinalReport.pdf [accessed 12th October 2012]

[12] Canadian Medical Association (CMA). Press Release: More Support for Principles to Guide Health Care Transformation. Available from: http://www.cma.ca/multimedia/CMA/Content_Images/Inside_cma/Media_Release/2012/Support-for-Joint-Principles_en.pdf [accessed 12th October 2012] 